\title{
Relationship Between the Consumption of Soy and Its Derivatives During Critical Periods of Development and in Adulthood and Endocrine-Metabolic Disorders
}

\author{
Adriana M. Vieira ${ }^{a}$, Poliana Guiomar A. Brasiel ${ }^{\text {b d }}$, Maira S. Ferreira ${ }^{a}$, Aline S. Aguiarc \\ Sheila Cristina P.D. Luquettic
}

\begin{abstract}
The consumption of soybeans and their constituents, isolated soy protein and isoflavones, has been associated with positive effects on body weight, lipid profile and insulin, which has stimulated the production and consumption of foods derived from soy. However, these polyphenolic compounds (isoflavones) have similar structure to 17- $\beta$ estradiol and may act as agonists or antagonists in estrogen receptors. Due to its estrogenic activity, the safety of its consumption during critical periods of development, such as gestation and lactation, has been questioned. Studies that evaluate the effects of soybeans on endocrine metabolic parameters are still controversial. This review focuses on the role that soy and isoflavones play during critical periods of development and into adulthood.
\end{abstract}

Keywords: Soy; Metabolic programming; Fetal programming; Isoflavones

\section{Introduction}

The soybean (Glycine max (1.) Merrill) is a plant of oleaginous high nutritional value, having high protein content $(40 \%)$ and fat $(20 \%)$, mostly unsaturated (23\% monounsaturated fat, $8 \%$ from $54 \%$ linoleic and linolenic) [1]. This legume and its constituents, isolated soy protein (ISP) and isoflavones, have been widely studied. Its possible beneficial effects on the body include the reduction of the levels of total cholesterol, lowdensity lipoprotein (LDL) cholesterol, triglyceride, and insulin resistance, as well as the fatness and body mass. Soy and its isoflavones appear to reduce the risk for coronary heart dis-

Manuscript submitted September 7, 2017, accepted September 20, 2017

aProgram in Health and Nutrition, Nutrition School, Federal University of Ouro Preto, MG, Brazil

bUniversity Hospital UFJF, Federal University of Juiz de Fora, MG, Brazil 'Department of Nutrition, Federal University of Juiz de Fora, MG, Brazil ${ }^{\mathrm{d} C}$ Corresponding Author: Poliana Guiomar Brasiel, Jose Lourenco Kelmer Street, Sao Pedro, 36036900, Juiz de Fora, MG, Brazil.

Email: guidinhabra@hotmail.com

doi: https://doi.org/10.14740/jem449w ease, but the mechanisms involved are still unknown, and its action on high-density lipoprotein (HDL) metabolism may be responsible for its anti-atherogenic effects [2-7]. These benefits have boosted the production of foods and supplements with these compounds for the food industry and its consumption by the population [8].

Isoflavones, polyphenolic compounds, possess structure similar to the 17- $\beta$-estradiol and can act as antagonist or agonist receptors for estrogens in the body [9]. Because of this estrogenic activity, the safety of its consumption in critical phases of development, as the gestation and lactation, has been questioned [10-12], as they may act as hormonal disruptors key systems that control the growth and development, permanent structural changes, generating metabolic and functional tissues and organism systems that can be attached to the development of chronic diseases; this process is called programming [13].

Another important aspect is to compare different sources of protein (soy protein or casein) nutritionally balanced diets during pregnancy or pregnancy and lactation, and it was possible to notice that soy protein is able to lead to increased risk factors for metabolic syndrome in male offspring in adulthood, and that exposure to these diets for a longer period (gestation and lactation) exacerbates the signs introduced [14, 15].

So considering the impact of nutritional and hormonal disorders in pregnancy and lactation on the offspring in adulthood, as well as the growing consumption of soy and its components, this systematic review aimed to identify the consequences of early exposure to soy, on endocrine-metabolic parameters in adult life.

\section{Methods}

A search through PubMed database, Scielo, Medline, using the keywords "phytoestrogens and fetal programming", "soy and fetal programming", "soy protein and fetal programming", and "metabolic programming" selected 105 articles published over the past 20 years. From this search, were selected 44 items that approached the endocrine-metabolic effects of soy consumption and its components on the body in critical phases of development (pregnancy and lactation) or in adult life. Thirteen references were not squared on the criterion of inclusion, but were used for description of the concept, etiology and patho- 
physiology of metabolic programming.

\section{Metabolic Programming}

The period of intrauterine development can expose the fetus to a risk of developing diseases in adulthood. In this respect, the hypothesis named Developmental Origins of Health and Disease (DOHaD) highlights the relationship between the stimuli in early stages of life and the subsequent development of disease. This model investigates the adaptations that occur in the fetus in response to intrauterine environment, resulting in permanent set of homeostatic systems in order to assist in the immediate survival and improve the success in an environment adverse postnatal. However, inappropriate interpretations or environmental changes can lead to a mismatch between the prenatal forecasts and postnatal reality [16-18].

In this way, these adaptations known as predictive, adaptive responses can be disadvantageous in adulthood, leading to an increased risk of diseases that can be passed on to future generations. In this perspective, it has been established that nutritional changes early in life involve an increased risk for a number of diseases in adulthood [19].

Several studies have shown association between maternal malnutrition and exposure to hormones during pregnancy and lactation, with future metabolic disorders, with emphasis on non-communicable chronic diseases, thyroid disorders, and components of the metabolic syndrome [13, 19-22]. The type of malnutrition that the mother is subjected is able to interfere in the nutritional status of adult offspring. In cubs whose mother suffered during lactation, protein restriction showed low body weight of weaning at 6 months of age. Already the calorie restriction led to offspring in adulthood (6 months), to gain more weight compared to the control, and to develop a resistance to anorectic action of the hormone leptin [23].

Thus, it is possible to note that the programming in critical phase of development can lead to changes in tissues and organs, which extend over the life, and may also have a latency period and only occur manifestations of adult life. More and more studies come popping up in order to explain the possible mechanisms related to metabolic programming.

These mechanisms have not yet been fully elucidated, but it is believed that there is a relationship with changes in the structural development of the organs, or persistent changes at the cellular level, being postulated according to Koletzko et al [24]: 1) participation of epigenetic memory, with modification in the process of transcription; 2) changing the structure of organs in vascularity, innervation and juxtaposition, as for example, the position of the hepatocytes, endothelial cells and Kuppfer cells, which during the organogenesis can modify the metabolism permanently; 3 ) hyperplasia or hypertrophy occur, leading to changes in the number of cells; 4) abnormal cell growth of rapid proliferation in specific metabolic conditions (clonal selection); and 5) metabolic differentiation process.

Note that the molecular mechanisms proposed include acute or chronic changes in gene expression, through various avenues, where there is an epigenetic interrelation between certain genes, exposure to environmental factors and biologi- cal events [25]. Since epigenetic regulation during development changes, the dynamic epigenome presents an unstable nature, allowing you to respond and adapt to environmental pressures, including nutritional modifications [26].

Still, there is much to be understood, although epigenetics help understand how exposure to environmental factors, in critical periods of development, leads to changes in adult life; it is necessary to unravel the changes post-translational involved in the various processes that lead to the emergence of diseases [27].

\section{Soybean and Metabolic Effects}

Although there is no consensus among authors, the beneficent effects of the soy have been attributed mainly to the isoflavones and ISP, which includes isoflavones. It is noteworthy that the isoflavones have a structure similar to that of $17-\beta$-estradiol and may act as phytoestrogens, that is, substances similar to the hormone estrogen, being able to interact as agonist form or antagonist with their receptors in the body [9, 27].

In the estrogenic action, the isoflavones, mainly the genistein, play other functions in the organism, acting on the growth and regulation of various cell types. It has been evidenced it is a promising alternative for the prevention and treatment of some cancers, cardiovascular disease, prevention of metabolic syndrome, osteoporosis and decreased symptoms of menopause [6,28].

Innumerous studies show the role of soy in control of several morbidities, leading to improvement in plasma levels of blood glucose, with decreased insulin levels and insulin resistance, as well as decreased hepatic steatosis, adiposity and body weight $[4,5,29,30]$.

Ferguson et al [31] evaluated the relationship between consumption of foods containing isoflavones on the inflammatory response caused by the transient endotoxemia, noticing an increase of the immune response related to the consumption of isoflavones. Furthermore, there was protection on induced inflammation by decline of insulin resistance, and better response to oral glucose tolerance test [31].

Likewise, the ISP consisting of trypsin inhibitor and chymotrypsin, whose intake is associated with reduction in weight gain in animals, has been pointed as capable of reducing serum insulin and resistance to his action, enhancing the hyperglycemia frame and acting in the control of diabetes [2]. In addition, studies show anticarcinogenic effects of its constituents [32].

Regarding lipids, it has been demonstrated that consumption of soy, of isoflavones and/or of ISP, reduces total cholesterol levels, LDL and triacylglycerols [3]. In this aspect, isoflavones and ISP are capable of regulating the expression of various genes and enzymes involved in anabolism and catabolism of lipids in various tissues, leading to increased oxidation of fatty acids, less accumulation of lipids in adipocytes and skeletal muscles [33-36].

Moreover, these compounds are capable of acting on the levels of leptin and adiponectin, hormones secreted by the adipose tissue that participate in the regulation of several metabolic pathways. The studies have shown adverse effects on 
these hormones, having increased levels of adiponectin [3740], and decreased levels of leptin [33, 35, 37, 41]. However, there is divergence between these findings, being pointed by some authors the increased circulating leptin and decreased adiponectin [42, 43].

In relation to food intake and weight gain of the animals fed soy or any of its components, there is evidence to suggest the not modification of these parameters in relation with the control group $[33,35,37]$. However, a lower weight gain in animals fed soy was demonstrated compared to the casein group, and eating a high fat diet with soybean led to less weight gain of animals compared to the group who ingested only a high-fat diet $[38,44]$.

In spite of existing controversy in the literature on the effect of soy in some metabolic endocrine parameters, there is strong evidence of the benefits of soy in morbidities control [2, $6,28,31]$. However, some studies have questioned the safety of early introduction of foods that contain phytoestrogens in its composition, which can cause long-term hormonal changes, leading to the development of pathologies in adulthood [10, $14,15,45]$.

\section{Soy and Metabolic Programming}

Several studies suggest that soy-based diets containing phytoestrogens, when consumed in pregnancy and during lactation, can act as key systems hormonal disruptors that control the growth and development, due to the estrogenic activity of these compounds [10-12].

In the context of this discussion, it is important to emphasize the ability of placental transfer of phytoestrogens from mother to fetus $[46,47]$. In this sense, 51 Japanese mothers were accompanied by the time of cesarean section, where we collected serum sample of the mother and the umbilical cord. The detection rates of phytoestrogens, genistein, daidzein and equol in the umbilical cord of the newborns were $100 \%, 80 \%$ and $35 \%$, respectively [46]. Within this perspective, Nagata et al [47] also showed high correlations to isoflavone levels between samples of maternal and umbilical cord blood of 194 accompanied women during pregnancy [47].

It should be noted that exposure to soy or any of its components may occur during the period of lactation, as was evidenced by the transfer of phytoestrogens via breast milk [48, 49]. Cederroth and Nef [50] showed that maternal exposure on lactation to a diet rich in phytoestrogens, approximately $25 \%$ of soy protein, decreased weight and adiposity, without affecting the response to glucose tolerance in male puppies in adulthood. Already the soy exposure in pregnancy did not alter the weight and adiposity, but improved the response to glucose tolerance in adult offspring. Thus, it is possible that the metabolic effects of soy are dependent on the period of life in which the exposure occurs [50].

Jahan-Mihan et al [14] showed that male puppies whose mothers were fed with diet of soy protein in pregnancy had higher body weight in ninth and 15 th weeks, as well as increased fasting blood glucose, insulin, and HOMA-IR index. The results suggest that soy protein when compared with ca- sein during gestation or pregnancy and lactation increases the risk of developing metabolic syndrome characteristics in the offspring [14].

Male pups whose mothers were fed with different concentrations of isoflavones $(0,5,50$, or $1,000 \mathrm{ppm})$, during gestation and lactation, did not show difference in weight at 21 and 90 days. However, the concentration of $50 \mathrm{ppm}$ led to increased serum concentration of leptin and adiponectin in relation to the other concentrations, suggesting a dose-dependent effect. It was further evidenced the ability of adiponectin in acting on cells from testicular Leyding, affecting the hormone production of these animals [12].

Other works point to the toxic effects of phytoestrogens on reproduction and may cause abnormalities in the estrous cycle, and changes in ovarian and testicular function, leading to the development of precocious puberty in female offspring and decreased production of testosterone in male offspring $[11,51]$. Using organ cultures of fetal testes from wild type and ER $\alpha$ or ER $\beta$ knock-out mice, it was shown that genistein inhibits testosterone secretion by fetal Leydig cells during early fetal development [51].

However, Ruhlen et al [10] have demonstrated in mice that low concentration of phytoestrogens from soy on maternal ration during gestation and lactation promotes an increase of endogenous estradiol, which was associated with adverse effects on the reproductive system and on the nutritional status of the male puppies in adulthood. They became obese, insulinresistant hyperleptinemic. Animals exposed to the diet rich in phytoestrogens from soy have developed these changes [10].

In this way, not always soy consumption in relation to programming relates to negative way. A survey pointed out that female rats receiving genistein and quercetin during pregnancy scheduled the offspring in adulthood to the increased expression of several genes enzymatic antioxidants, primarily in the liver, resulting in significantly lower levels of oxidative damage on DNA [52]. In addition, mice that are exposed to a diet deficient in isoflavones during pregnancy and in adult life had increased oxidative stress, decreased antioxidant enzymes and levels of nitric oxide synthase, endothelial dysfunction and arterial [53].

Consistent with this idea, Linz et al [54], in the study on carcinogenesis, have shown that the offspring of rats fed with ISP, and who received the same maternal diet after weaning, showed a reduction in the frequency of carcinoma, clarifying the role of ISP in the prevention of colon cancer [54].

The maternal consumption of $20 \%$ of soy protein in pregnancy and lactation, and the continuation for the offspring until 48 days of life, increased expression of thyroid hormone receptor (TR $\beta 1$ ), as well as the expression and activity of iodothyronines deiodinases (D1 and D2) in the liver of rats, and suggested that these effects mediate the action of hormones thyroid contributing to reduction of serum cholesterol, the fatty liver and body weight [5].

Other studies have demonstrated beneficial effects of soy consumption during gestation and lactation, leading to reduced body weight, improved insulin sensitivity, and reduced blood glucose and total cholesterol levels and triglycerides [4, 5, 50, 55]. However, there are some differences in the literature, although further research is needed in order to clarify the real 
contribution of soybean.

\section{Conclusions}

Several studies about soy and its derivatives presented a broad vision of its beneficial effect on the human organism, being these properties broadcast to all population. However, their possible adverse effects are part of relatively new research, and the increasing consumption of soy-based foods extends the importance of studying the actions of these compounds to the human organism.

The use of soy source foods in critical periods of development may be related to positive or negative effects, presented in experiments with animals. Thus there is a need for further studies involving the consumption of these foods, especially in pregnancy, lactation and childhood, in order to know the real effect of these dietary estrogens on the process of health and illness.

\section{Acknowledgments}

The authors would like to thank Kacia Mateus and Franciane Toledo for their support during the preparation of this manuscript.

\section{Conflict of Interest}

None.

\section{References}

1. Miura EMY, Binotti MAR, Camargo DS, et al. Avaliacao biologica da soja com baixas atividades de inibidores de tripsina e ausencia do inibidor Kunitz. Arch Latinoam Nutr. 2001;51:195-198.

2. Bhathena SJ, Velasquez MT. Beneficial role of dietary phytoestrogens in obesity and diabetes. Am J Clin Nutr. 2002;76(6):1191-1201.

3. Zhan S, Ho SC. Meta-analysis of the effects of soy protein containing isoflavones on the lipid profile. Am J Clin Nutr. 2005;81(2):397-408.

4. Cederroth CR, Vinciguerra M, Gjinovci A, Kuhne F, Klein M, Cederroth M, Caille D, et al. Dietary phytoestrogens activate AMP-activated protein kinase with improvement in lipid and glucose metabolism. Diabetes. 2008;57(5):1176-1185.

5. Simmen FA, Mercado CP, Zavacki AM, Huang SA, Greenway AD, Kang P, Bowman MT, et al. Soy protein diet alters expression of hepatic genes regulating fatty acid and thyroid hormone metabolism in the male rat. $\mathrm{J}$ Nutr Biochem. 2010;21(11):1106-1113.

6. Jungbauer A, Medjakovic S. Phytoestrogens and the metabolic syndrome. J Steroid Biochem Mol Biol. 2014;139:277-289.
7. Yanai H, Katsuyama H, Hamasaki H, et al. Effects of soy protein and isoflavones intake on HDL metabolism in Asian populations. J Endocrinol Metab. 2014;4:51-55.

8. Setchell KD, Brown NM, Desai P, Zimmer-Nechemias L, Wolfe BE, Brashear WT, Kirschner AS, et al. Bioavailability of pure isoflavones in healthy humans and analysis of commercial soy isoflavone supplements. J Nutr. 2001;131(4 Suppl):1362S-1375S.

9. Peron AP, Santos JF, Mantovani D, et al. Utilizacao das isoflavonas presentes na soja (Glycine max (L) Merril) na prevencao e tratamento de doencas cronicas - uma breve revisao. Arq Mudi. 2008;12:51-57.

10. Ruhlen RL, Howdeshell KL, Mao J, Taylor JA, Bronson FH, Newbold RR, Welshons WV, et al. Low phytoestrogen levels in feed increase fetal serum estradiol resulting in the "fetal estrogenization syndrome" and obesity in CD-1 mice. Environ Health Perspect. 2008;116(3):322-328.

11. Cederroth CR, Zimmermann C, Beny JL, Schaad O, Combepine C, Descombes P, Doerge DR, et al. Potential detrimental effects of a phytoestrogen-rich diet on male fertility in mice. Mol Cell Endocrinol. 2010;321(2):152160.

12. Pfaehler A, Nanjappa MK, Coleman ES, Mansour M, Wanders D, Plaisance EP, Judd RL, et al. Regulation of adiponectin secretion by soy isoflavones has implication for endocrine function of the testis. Toxicol Lett. 2012;209(1):78-85.

13. de Moura EG, Passos MC. Neonatal programming of body weight regulation and energetic metabolism. Biosci Rep. 2005;25(3-4):251-269.

14. Jahan-Mihan A, Smith CE, Anderson GH. Effect of protein source in diets fed during gestation and lactation on food intake regulation in male offspring of Wistar rats. Am J Physiol Regul Integr Comp Physiol. 2011;300(5):R11751184.

15. Jahan-mihan A, Smith CE, Hamedani A, Anderson GH. Soy protein-based compared with casein-based diets fed during pregnancy and lactation increase food intake and characteristics of metabolic syndrome less in female than male rat offspring. Nutr Res. 2011;31(8):644-651.

16. Gluckman PD, Hanson MA, Cooper C, Thornburg KL. Effect of in utero and early-life conditions on adult health and disease. N Engl J Med. 2008;359(1):61-73.

17. Laker RC, Wlodek ME, Connelly JJ, Yan Z. Epigenetic origins of metabolic disease: The impact of the maternal condition to the offspring epigenome and later health consequences. Food Science and Human Wellness. 2013;2:111.

18. Chango A, Pogribny IP. Considering maternal dietary modulators for epigenetic regulation and programming of the fetal epigenome. Nutrients. 2015;7(4):2748-2770.

19. Fernandez-Twinn DS, Ozanne SE. Early life nutrition and metabolic programming. Ann N Y Acad Sci. 2010;1212:78-96.

20. Passos MC, Toste FP, Dutra SC, Trotta PA, Toste FP, Lisboa PC, de Moura EG. Role of neonatal hyperleptinaemia on serum adiponectin and suppressor of cytokine signalling-3 expression in young rats. Br $\mathrm{J}$ Nutr. 2009;101(2):250-256. 
21. Lisboa PC, Fagundes AT, Denolato AT, Oliveira E, Bonomo IT, Alves SB, Curty FH, et al. Neonatal low-protein diet changes deiodinase activities and pituitary TSH response to TRH in adult rats. Exp Biol Med (Maywood). 2008;233(1):57-63.

22. Moura EG, Santos RS, Lisboa PC, Alves SB, Bonomo IT, Fagundes AT, Oliveira E, et al. Thyroid function and body weight programming by neonatal hyperthyroidism in rats - the role of leptin and deiodinase activities. Horm Metab Res. 2008;40(1):1-7.

23. Passos MC, Vicente LL, Lisboa PC, de Moura EG. Absence of anorectic effect to acute peripheral leptin treatment in adult rats whose mothers were malnourished during lactation. Horm Metab Res. 2004;36(9):625-629.

24. Koletzko B, Symonds ME, Olsen SF, et al. Programming research: where are we and where do we go from here? Am Clin Nutr. 2011;94:2036-2043.

25. Hanley B, Dijane J, Fewtrell M, Grynberg A, Hummel S, Junien C, Koletzko B, et al. Metabolic imprinting, programming and epigenetics - a review of present priorities and future opportunities. Br J Nutr. 2010;104(Suppl $1): \mathrm{S} 1-25$.

26. Vickers MH. Early life nutrition, epigenetics and programming of later life disease. Nutrients. 2014;6(6):21652178 .

27. Kostelac D, Rechkemmer G, Briviba K. Phytoestrogens modulate binding response of estrogen receptors alpha and beta to the estrogen response element. J Agric Food Chem. 2003;51(26):7632-7635.

28. Bedani R, Rossi EA. Isoflavonas: Bioquimica, Fisiologia e Implicacoes para a Saude. B. CEPPA. 2005;23:231-264.

29. Noriega-Lopez L, Tovar AR, Gonzalez-Granillo M, Hernandez-Pando R, Escalante B, Santillan-Doherty P, Torres N. Pancreatic insulin secretion in rats fed a soy protein high fat diet depends on the interaction between the amino acid pattern and isoflavones. J Biol Chem. 2007;282(28):20657-20666.

30. Velasquez MT, Bhathena SJ. Role of dietary soy protein in obesity. Int J Med Sci. 2007;4(2):72-82.

31. Ferguson JF, Ryan MF, Gibney ER, Brennan L, Roche HM, Reilly MP. Dietary isoflavone intake is associated with evoked responses to inflammatory cardiometabolic stimuli and improved glucose homeostasis in healthy volunteers. Nutr Metab Cardiovasc Dis. 2014;24(9):9961003.

32. Penha LAO, Fonseca ICB, Mandarino JM, Benassi VT. A soja como alimento: valor nutricional, benefícios para a saude e cultivo organico. B. CEPPA. 2007;25:91-102.

33. Frigolet ME, Torres N, Uribe-Figueroa L, Rangel C, Jimenez-Sanchez G, Tovar AR. White adipose tissue genome wide-expression profiling and adipocyte metabolic functions after soy protein consumption in rats. J Nutr Biochem. 2011;22(2):118-129.

34. Park HJ, Della-Fera MA, Hausman DB, Rayalam S, Ambati S, Baile CA. Genistein inhibits differentiation of primary human adipocytes. J Nutr Biochem. 2009;20(2):140148.

35. Yang H, Li F, Xiong X, Kong X, Zhang B, Yuan X, Fan J, et al. Soy isoflavones modulate adipokines and myokines to regulate lipid metabolism in adipose tissue, skeletal muscle and liver of male Huanjiang mini-pigs. Mol Cell Endocrinol. 2013;365(1):44-51.

36. Palacios-Gonzalez B, Zarain-Herzberg A, Flores-Galicia I, Noriega LG, Aleman-Escondrillas G, Zarinan T, UlloaAguirre A, et al. Genistein stimulates fatty acid oxidation in a leptin receptor-independent manner through the JAK2-mediated phosphorylation and activation of AMPK in skeletal muscle. Biochim Biophys Acta. 2014;1841(1):132-140.

37. Nagasawa A, Fukui K, Kojima M, Kishida K, Maeda N, Nagaretani H, Hibuse T, et al. Divergent effects of soy protein diet on the expression of adipocytokines. Biochem Biophys Res Commun. 2003;311(4):909-914.

38. Jang EH, Moon JS, Ko JH, Ahn CW, Lee HH, Shin JK, Park CS, et al. Novel black soy peptides with antiobesity effects: activation of leptin-like signaling and AMP-activated protein kinase. Int J Obes (Lond). 2008;32(7):11611170 .

39. Yamada Y, Muraki A, Oie M, et al. Soymorphin-5, a soyderived $\mu$-opioid peptide, decreases glucose and triglyceride levels through activating adiponectin and PPAR $\alpha$ systems in diabetic KKAy mice. Am J Physiol Endocrinol Metab. 2012;302:433-440.

40. Yanagisawa M, Sugiya M, Iijima H, Nakagome I, Hirono $\mathrm{S}$, Tsuda T. Genistein and daidzein, typical soy isoflavones, inhibit TNF-alpha-mediated downregulation of adiponectin expression via different mechanisms in 3T3L1 adipocytes. Mol Nutr Food Res. 2012;56(12):17831793.

41. Szkudelski T, Nogowski L, Pruszynska-Oszmalek E, Kaczmarek P, Szkudelska K. Genistein restricts leptin secretion from rat adipocytes. J Steroid Biochem Mol Biol. 2005;96(3-4):301-307.

42. Giordano E, Davalos A, Crespo MC, Tome-Carneiro J, Gomez-Coronado D, Visioli F. Soy isoflavones in nutritionally relevant amounts have varied nutrigenomic effects on adipose tissue. Molecules. 2015;20(2):23102322.

43. Wagner JD, Zhang L, Shadoan MK, Kavanagh K, Chen $\mathrm{H}$, Tresnasari K, Kaplan JR, et al. Effects of soy protein and isoflavones on insulin resistance and adiponectin in male monkeys. Metabolism. 2008;57(7 Suppl 1):S24-31

44. Torre-Villalvazo I, Tovar AR, Ramos-Barragan VE, Cerbon-Cervantes MA, Torres N. Soy protein ameliorates metabolic abnormalities in liver and adipose tissue of rats fed a high fat diet. J Nutr. 2008;138(3):462-468.

45. Liu M, Yanagihara N, Toyohira Y, Tsutsui M, Ueno S, Shinohara Y. Dual effects of daidzein, a soy isoflavone, on catecholamine synthesis and secretion in cultured bovine adrenal medullary cells. Endocrinology. 2007;148(11):5348-5354.

46. Todaka E, Sakurai K, Fukata H, Miyagawa H, Uzuki M, Omori M, Osada H, et al. Fetal exposure to phytoestrogens--the difference in phytoestrogen status between mother and fetus. Environ Res. 2005;99(2):195-203.

47. Nagata C, Iwasa S, Shiraki M, Ueno T, Uchiyama S, Urata K, Sahashi Y, et al. Associations among maternal soy intake, isoflavone levels in urine and blood samples, and 
maternal and umbilical hormone concentrations (Japan). Cancer Causes Control. 2006;17(9):1107-1113.

48. Weber KS, Setchell KD, Lephart ED. Maternal and perinatal brain aromatase: effects of dietary soy phytoestrogens. Brain Res Dev Brain Res. 2001;126(2):217-221.

49. Doerge DR, Twaddle NC, Churchwell MI, Newbold RR, Delclos KB. Lactational transfer of the soy isoflavone, genistein, in Sprague-Dawley rats consuming dietary genistein. Reprod Toxicol. 2006;21(3):307-312.

50. Cederroth CR, Nef S. Fetal programming of adult glucose homeostasis in mice. PLoS One. 2009;4(9):e7281.

51. Lehraiki A, Chamaillard C, Krust A, Habert R, Levacher C. Genistein impairs early testosterone production in fetal mouse testis via estrogen receptor alpha. Toxicol In Vitro. 2011;25(8):1542-1547.

52. Vanhees K, van Schooten FJ, van Waalwijk van DoornKhosrovani SB, van Helden S, Munnia A, Peluso M,
Briede JJ, et al. Intrauterine exposure to flavonoids modifies antioxidant status at adulthood and decreases oxidative stress-induced DNA damage. Free Radic Biol Med. 2013;57:154-161.

53. Bonacasa B, Siow RC, Mann GE. Impact of dietary soy isoflavones in pregnancy on fetal programming of endothelial function in offspring. Microcirculation. 2011;18(4):270-285.

54. Linz AL, Xiao R, Parker JG, Simpson PM, Badger TM, Simmen FA. Feeding of soy protein isolate to rats during pregnancy and lactation suppresses formation of aberrant crypt foci in their progeny's colons: interaction of diet with fetal alcohol exposure. J Carcinog. 2004;3(1):14.

55. Dolinoy DC, Weidman JR, Waterland RA, Jirtle RL. Maternal genistein alters coat color and protects Avy mouse offspring from obesity by modifying the fetal epigenome. Environ Health Perspect. 2006;114(4):567-572. 